\title{
1 Soil-microbes-mediated invasional meltdown in plants
}

3 Zhijie Zhang ${ }^{1}$, Yanjie Liu ${ }^{2 *}$, Caroline Brunel ${ }^{3,4}$, Mark van Kleunen ${ }^{1,3}$

$4 \quad{ }^{1}$ Ecology, Department of Biology, University of Konstanz, 78464 Konstanz, Germany

$5 \quad{ }^{2}$ Key Laboratory of Wetland Ecology and Environment, Northeast Institute of

6 Geography and Agroecology, Chinese Academy Sciences, Changchun 130102, China

$7{ }^{3}$ Zhejiang Provincial Key Laboratory of Plant Evolutionary Ecology and

8 Conservation, Taizhou University, Taizhou 318000, China

$9 \quad{ }^{4}$ IRD, IPME; 911 avenue Agropolis, BP 64501, 34394, Montpellier, France

$11 *$ Email of corresponding author: liuyanjie@iga.ac.cn +86 43185542266 


\section{Abstract}

14 While most alien species fail to establish, some invade native communities and

15 become widespread. Many of these communities have been invaded by multiple

16 aliens, suggesting that aliens may cause invasional meltdowns. Here, we tested

17 whether and how a third plant species affects the competitive outcome between alien

18 and native plants through its soil legacy. We first conditioned soil with one of ten

19 species (six natives and four aliens) or without plants. Then, we grew on these 11

20 soils, five aliens and five natives without competition, and with intra- or interspecific

21 competition (all pairwise alien-native combinations). We found that aliens were not

22 more competitive than natives when grown on soil conditioned by other natives or on

23 non-conditioned soil. However, aliens were more competitive than natives on soil

24 conditioned by other aliens. Although soil conditioning rarely affected the strength of

25 competition between later plants, soil conditioned by aliens changed the competitive

26 outcomes by affecting growth of aliens less negatively than that of natives.

27 Microbiome analysis confirmed this finding by showing that the soil-legacy effects of

28 one species on later species were less negative when their fungal endophyte

29 communities were less similar; and that fungal endophyte communities were less

30 similar between two aliens than between aliens and natives. Our study suggests that

31 coexistence between aliens and natives is less likely with more alien species. Such

32 invasional meltdown is likely mediated by spill-over of fungal endophytes, some of

33 which are pathogenic.

35 Keywords: competition, endophytes, enemy release, alien species, multispecies,

36 novelty, plant-soil feedback, soil biota 
37

\section{Introduction}

What determines invasion success of alien species is a central and urgent question in ecology ${ }^{1}$. Charles Elton, in his famous book, posited superior competitive ability as one of the mechanisms ${ }^{2}$. Since then, hundreds of experiments have studied competition between native and alien species, confirming that many successful alien species are indeed more competitive than natives ${ }^{3-5}$. Most studies, however, focused on pairwise interactions ${ }^{6}$ (i.e. between an alien and a native species; but see $\operatorname{ref}^{7-9}$ for studies of multispecies interactions), although in nature most species interact with multiple species. Moreover, interactions between alien species have also been frequently observed ${ }^{10}$. In many cases, aliens appear to favor other aliens over natives $^{11,12}$, a phenomenon called invasional meltdown ${ }^{13}$. Still, invasional meltdown has so far mainly been studied in pairs of alien species without considering interactions with native species ${ }^{14,15}$. Therefore, the competitive outcome between alien and native species in multispecies communities remains unknown.

A major challenge in community ecology is to predict competitive outcomes in multispecies communities (e.g. to predict which species will dominate). Many studies suggest that outcomes in multispecies communities could be predicted from twospecies systems, by assuming that interactions remain pairwise in all systems ${ }^{16-18}$, which. For a hypothetical example, consider adding a third species into a two-species community (Fig. 1b). If we know from previous pairwise experiments that the third species strongly suppresses one of the two species, we would predict that it will indirectly release the other species from competition. Although this 'bottom-up' approach is supported by several experiments on microbes ${ }^{19,20}$, the effect of one competitor on another (i.e. the strength of competition) can be changed by a third species $^{21,22}$ (Fig. 1c \& d). For example, it was shown that Skeletonema costatum, a 
62 cosmopolitan diatom, does not directly affect the growth of Karenia brevis, a dominant dinoflagellate in the Gulf of Mexico, but undermines the allelopathic effects of $K$. brevis ${ }^{23}$. This would also lessen the effect of $K$. brevis on other phytoplankton species, and interactions might consequently not always remain pairwise. Therefore, we need to test how the competitive outcome between alien and native species is affected by other species explicitly.

Competition occurs through different processes, which makes it challenging to study. The most widely studied process is resource competition ${ }^{24}$, partly because competition for space, food and other resources is the most intuitive. Nevertheless, growing evidence shows that resource use alone cannot always explain success of alien species ${ }^{25-27}$. Competition can also act through other trophic levels. This so-called apparent competition ${ }^{28}$ has been extensively studied in systems in which plants affect others through shared aboveground herbivores ${ }^{6,7}$. The last two decades, however, has also seen an increased interest in apparent competition mediated by soil microbes. More and more studies reveal that plants modify soil microbes with consequences for their own development, and affecting plants that grow subsequently on the soil ${ }^{29-33}$ (a mechanism that we hereafter refer to as a soil-legacy effect).

Studies on soil-legacy effects have opened up new avenues to test mechanisms of plant invasion ${ }^{34}$, such as enemy release $\mathrm{s}^{35-37}$ and novelty of aliens ${ }^{38,39}$. Based on these mechanisms, we would expect that the origin (alien or native) of the third species matters in how they affect competitive outcomes between alien and native species. First, enemy release posits that alien plants are released from their enemies ${ }^{40}$, and therefore soil conditioned by alien plants should accumulate few soil pathogens. Consequently, aliens would free natives that grow later on that soil from pathogens, unless they accumulate pathogens that are highly toxic to natives ${ }^{41}$. However, if aliens 
87 grow later on the soil, they might not be affected because they are already released from pathogens. Following this logic, soil conditioned by aliens would subsequently favor natives over aliens. Second, natives are familiar to (i.e. co-evolve with) each other, whereas aliens and natives are novel to each other (i.e. lack of coevolution) $)^{39,42}$.

91 Therefore, natives should accumulate soil pathogens that are more likely shared with 92 other natives than with aliens. Following this logic, soil conditioned by natives would 93 subsequently favor aliens over natives. Whether these two expectations hold remains 94 unknown.

To date, the competitive outcome between alien and native plants in multispecies communities remains unclear. We tested this with a large multi-species experiment. We first conditioned soil with one of ten species (six natives and four aliens) or, as a control, without plants. Then, on each of these 11 soils, five alien and five native test species were grown without competition, and with intraspecific or interspecific competition, using all pairwise alien-native combinations. To assess the

101 potential role of microbes, we also analyzed the relationship between soil 102 communities and soil-legacy effects. We addressed the following questions: (1) Does

103 a third species (i.e. a soil-conditioning species) affect the competitive outcome 104 between subsequent alien and native test species through a soil-legacy effect ( $\beta_{\text {total }}$, the 105 net effect of $\beta_{\text {alone, }} \beta_{\text {inter }}$ and $\beta_{\text {intra }}$ in Fig. 1), and does the origin (native or alien) of the 106 third species matter? (2) If so, does the third species affect competitive outcomes 107 through its soil-legacy effect on the growth of test species $\left(\beta_{\text {alone }}\right)$, or through its soil108 legacy effect on the strength of competition $\left(\beta_{\text {inter }}\right.$ or $\left.\beta_{\text {intra }}\right)$ ? (3) Does variation in soil 109 microbial communities among the conditioned soils explain the variation in soil110 legacy effects ? 


\section{Materials and Methods}

\section{Study location and species}

113 We conducted our experiment in the Botanical Garden of the University of Konstanz,

114 Germany $\left(47.69^{\circ} \mathrm{N}, 9.18^{\circ} \mathrm{E}\right)$. We conditioned soil with one of four plant species that

115 are naturalized aliens in Germany and six plant species that are native to Germany.

116 For these 10 soil-conditioning species, we tested their soil-legacy effects on five

117 naturalized alien and five native species (test species; Table S1). The soil-

118 conditioning and test species partly overlapped, and in total we used seven alien and

119 six native species. We used multiple species to increase our ability to generalize the

120 results $^{43}$. The classification of the species as natives or naturalized aliens in Germany

121 was based on the FloraWeb database ${ }^{44}$. Among the seven alien species, three are

122 native to North America, one to Southern Africa, and three to other parts of Europe

123 (Table S1). All 13 species can be locally abundant and are widespread in Germany

124 (i.e. occur in at least $30 \%$ regions in Germany, see Table S1 for details). As

125 widespread species are likely to have high spread rates, the alien species can be

126 considered as invasive or probably invasive sensu Richardson, et al. ${ }^{45}$. All species

127 mainly occur in grasslands and overlap in their distributions according to FloraWeb,

128 and thus are very likely to co-occur in nature.

129 Seeds of the native species and one of the alien species (Onobrychis viciifolia)

130 were purchased from Rieger-Hofmann GmbH (Blaufelden-Raboldshausen, Germany).

131 Seeds of the other species were from the seed collection of the Botanical Garden of

132 the University of Konstanz. We initially planned to use the same species in the soil-

133 conditioning and test phases. However, in the soil-conditioning phase, seeds of one of

134 the six native species (Cynosurus cristatus) were contaminated with other species, and

135 germination success of two aliens (Solidago gigantea and Salvia verticillata) was low. 
136 Therefore, we replaced these three species in the test phase with three alien species

137 (Solidago canadensis, Senecio inaequidens and Epilobium ciliatum).

\section{Experimental setup}

\section{Soil-conditioning phase}

140 From 18 June to 2 July 2018 (Table S1), we sowed the four alien and six native soil-

141 conditioning species separately into trays $(10 \mathrm{~cm} \times 10 \mathrm{~cm} \times 5 \mathrm{~cm})$ filled with potting

142 soil (Topferde ${ }^{\circledR}$, Einheitserde Co., Germany). Seeds were not sterilized. Because we

143 wanted the different species to be in similar developmental stages at the beginning of

144 the experiment, we sowed the species at different times (Table S1), according to their

145 germination timing known from previous experiments. We placed the trays in a

146 greenhouse under natural light conditions, with a temperature between 18 and $25^{\circ} \mathrm{C}$.

147 For each species, we transplanted 135 seedlings individually into 1.5 -L pots.

148 This was done for eight out of ten species, and done from 9 to 11 July 2018. For the

149 other two species, Sa. verticillata and So. gigantea, we transplanted 61 and 115

150 seedlings respectively, from 25 July to 12 August (Table S1). This was because these

151 two species germinated more slowly and irregularly than foreseen. We also added 330

152 pots that did not contain plants as a control treatment. In a complete design, we would

153 have had 1680 pots. However, because we had fewer pots of C. cristatus. So. gigantea

154 and Sa. verticillata, we ended up with 1521 pots. The substrate that we used was a

155 mixture of $37.5 \%(\mathrm{v} / \mathrm{v})$ sand, $37.5 \%$ vermiculite and $25 \%$ field soil. The field soil

156 served as inoculum to provide a live soil microbial community, and was collected

157 from a grassland site in the Botanical Garden of the University of Konstanz on 12

158 June 2018. We removed plant materials and large stones by sieving the field soil

159 through a 1-cm mesh, and immediately thereafter stored it at $4{ }^{\circ} \mathrm{C}$ until the

160 transplanting. 
After the transplanting, we randomly assigned the pots to positions in four

162 greenhouse compartments $\left(23^{\circ} \mathrm{C} / 18^{\circ} \mathrm{C}\right.$ day/night temperature, no additional light).

163 Each pot sat on its own plastic dish to preserve water and to avoid cross-

164 contamination through soil solutions leaking from the bottoms of the pots. Seedlings

165 that died within two weeks after transplanting were replaced by new ones. All pots,

166 including both the ones with and without plants, were watered as needed, randomized

167 twice across the four compartments, and fertilized seven times during the soil-

168 conditioning phase with an NPK water-soluble fertilizer (Universol Blue ${ }^{\circledR}$, Everris,

169 Germany) at a concentration of $1 \%$ m/v. From 22 to 26 October 2018, 15 weeks after

170 the start of soil-conditioning phase, we harvested all soil. We cut aboveground

171 biomass at soil level and freed the soil from roots by sieving it through a 5-mm mesh.

172 The mesh was sterilized in between using $70 \%$ ethanol. For the pots in the control

173 treatment, the soil was also sieved through the mesh. Then, we put the sieved soil of

174 each pot separately into new 1-L pots, which were used in the test phase. So, as

175 recommended by Brinkman et al. $(2010)^{46}$, we did not pool soil from different pots in

176 order to ensure independence of replicates. The collected aboveground biomass was

177 dried at $70^{\circ} \mathrm{C}$ to constant weight, and weighed to the nearest $1 \mathrm{mg}$.

\section{Test phase}

179 From 9 to 18 October 2018, we sowed the five alien and five native test species

180 (Table S1) in a similar way as we had done for the species of the soil-conditioning

181 phase. On 29 and 30 October, we transplanted the seedlings into the 1-L pots filled

182 with soil from the soil-conditioning phase. Three competition treatments were

183 imposed (Fig. 2): 1) no competition, in which individuals were grown alone; 2)

184 intraspecific competition, in which two individuals of the same species were grown

185 together; 3 ) interspecific competition, in which one individual of an alien and one 
186 individual of a native species were grown together. We grew all ten species without 187 competition, in intraspecific competition, and in all 25 possible native-alien

188 combinations of interspecific competition. For the plants that were grown in non189 conditioned soil, we replicated each species without competition 12 times, and with 190 intraspecific competition and each interspecific native-alien combination six times.

191 For the plants that were grown on conditioned soil, we had three replicates for each 192 combination of a competition treatment (10 without competition, 10 with intraspecific 193 competition, 25 with interspecific competition) and soil-conditioning species (six 194 native and four alien). Because we had fewer replicates for soil conditioned with $C$. 195 cristatus, So. gigantea and Sa. verticillata, the final design had 1521 pots (and 2639 196 individuals) in the test phase.

197 We randomly assigned the pots to positions in three greenhouse compartments.

198 Each pot sat on its own plastic dish. Seedlings that died within two weeks after 199 transplanting were replaced with new ones. All plants were watered as needed, and 200 fertilized four times during the test phase with the same fertilizer as that in the soil201 conditioning phase. The pots were re-randomized across the three compartments on 20210 December 2018. On 8 and 9 January 2019, ten weeks after the transplanting, we 203 harvested all aboveground biomass of each plant. For the plants that were grown 204 alone, we washed the belowground biomass free from soil. This could not be done for 205 the plants with competition, as their roots were so tangled that we could not separate 206 them. The biomass was dried at $70^{\circ} \mathrm{C}$ to constant weight, and weighed to the nearest 1 $207 \mathrm{mg}$.

\section{Soil sampling, DNA extraction, amplicon sequencing and bioinformatics}

209 From 22 to 26 October 2018, when we harvested the soil from the soil-conditioning 210 phase, we randomly selected six pots of each of the ten soil-conditioning species. For 
211 each of these pots, we homogenized the soil and then put a random sample of 10-20

$212 \mathrm{ml}$ in sterile plastic tubes $(50 \mathrm{ml})$. We additionally collected soil from six of the pots

213 without plants. The 66 samples were immediately stored at $-80{ }^{\circ} \mathrm{C}$ until DNA

214 extraction.

215 We extracted DNA from $0.25 \mathrm{~g}$ of each soil sample using the DNeasy®

216 PowerSoil@ Kit (Qiagen, Hilden, Germany), following the manufacturer's protocol.

217 PCR amplifications and amplicon sequencing were then performed by Novogene

218 (Beijing China). The V3-V4 region of bacterial 16S rDNA gene was amplified in

219 triplicate with the universal primers 341F/806R (forward primer: 5'-

220 CCTAYGGGRBGCASCAG-3'; ;everse 5rimer:

221 GGACTACNNGGGTATCTAAT- ${ }^{, 47}$ ). The ITS2 region of the fungal rDNA gene

222 was amplified in triplicate with the primers specific to this locus (forward primer: 5'-

223 GCATCGATGAAGAACGCAGC-3'; ${ }^{\prime}$ reverse 5rimer:

224 TCCTCCGCTTATTGATATGC-3 ${ }^{48}$ ).

225 We processed the raw sequences with the DADA2 pipeline, which was designed

226 to resolve exact biological sequences (Amplicon Sequence Variants). After

227 demultiplexing, we removed the primers and adapter with the cutadapt package ${ }^{49}$. We

228 trimmed the $16 \mathrm{~S}$ sequences to uniform lengths. Sequences were then dereplicated, and

229 the unique sequence pairs were denoised using the dada2 package ${ }^{50}$. We then merged

230 paired-end sequences, and removed chimeras. We rarefied bacteria and fungi to

23130,000 and 9,500 reads, respectively, to account for differences in sequencing depth.

232 Three samples with lower reads for bacteria or fungi, and two samples with low

233 amplicon concentrations for fungi were excluded from analyses. For fungi, we

234 assigned the sequences to taxonomic groups using the UNITE ${ }^{51}$ database. Then, we

235 identified putative fungal functional groups that could affect plant fitness using the 
236 FUNGuild database ${ }^{52}$. Sequence variants assigned to arbuscular mycorrhizal fungi, 237 plant pathogens and endophytes represented respectively $<0.1 \%, 11.4 \%$ and $15.7 \%$ of

238 the total read abundance. Sixty-five sequence variants were assigned as both

239 pathogens and endophytes, representing $6.3 \%$ of the total read abundance. This

240 indicates that c. $40 \%$ of the assigned endophytes are pathogenic. Because assigned

241 arbuscular mycorrhizal fungi had extremely low abundance and were not detected in

24237 out of 62 soil samples, we did not analyze the data of arbuscular mycorrhizal

243 fungi.

\section{Statistical analyses}

245 All statistical analyses were done in $\mathrm{R}$, version $3.6 .1^{53}$. We provide the main

246 information for each model in the main text, and details (e.g. random effects, variance

247 structure) in Supplement S2.

\section{Analyses of plant performance}

249 To test whether soil-conditioning plants affected competitive outcomes between alien

250 and native species ( $\beta_{\text {total }}$, the net effect of $\beta_{\text {alone, }} \beta_{\text {intra }}$ and $\left.\beta_{\text {inter }}\right)$ and the strength of 251 competition ( $\beta_{\text {inter }}$ in Fig. 1c and $\beta_{\text {inter }}$ in Fig. 1d) in the test phase, we used a linear 252 mixed-effect model (Model.plant.1), as implemented in the $n l m e^{54}$ package. The 253 model included aboveground biomass of the test plants as the response variable, and 254 the soil-conditioning treatment (none, same species as the test species, native species, 255 alien species), competition treatment (no, intra- and interspecific competition), origin 256 of test species (native, alien) and their interactions as the fixed effects. A significant 257 interaction between competition treatment and soil-conditioning treatment would 258 indicate that soil-conditioning treatments affects the strength of competition. A 259 significant three-way interaction of competition treatment, soil-conditioning treatment 260 and origin of the test species would indicate that the soil-conditioning treatments 
261 affect the strength of competition of alien and native plants differently. A significant

262 interaction between soil-conditioning treatment and origin of the test species would

263 indicate that the soil-conditioning treatment affects biomass production of alien and

264 native test species differently, averaged across all competition treatments. In other

265 words, it would indicate that the soil-conditioning treatment affects the competitive

266 outcome between aliens and natives. Competitive outcome here refers to which

267 species will exclude or dominate over the other species at the end point for the

268 community $^{55}$. Most studies infer the competitive outcome by only growing the species

269 in mixture ${ }^{56}$. However, we inferred it from the average of plants without competition,

270 in monocultures and in mixtures. This method has the advantages that it better mimics

271 the dynamics of species populations across space and time $e^{5,57}$, and that it increases the

272 precision of estimating competitive outcomes ${ }^{55}$.

273 To test whether soil-conditioning plants directly affected growth of alien and 274 native species ( $\beta_{\text {alone }}$ in Fig. 1 b), we analyzed the subset of test plants grown without 275 competition with linear mixed-effect models (Model.plant.2). These models included 276 aboveground, belowground or total biomass of test plants as the response variables, 277 and soil-conditioning treatment, origin of the test species and their interaction as fixed 278 effects. For all mixed-effect models, the significance of fixed effect was assessed with 279 likelihood-ratio tests when comparing models with and without the effect of interest ${ }^{58}$.

280 The soil-conditioning treatment had four levels: 1) the soil was not conditioned 281 by any plant (non-conditioned soil), 2) the soil was conditioned by the same species 282 as the focal test plant (home soil), and if the soil was conditioned by another species, 283 this was either 3) an alien species (alien soil) or 4) a native species (native soil). We 284 created three dummy variables ${ }^{59}$ to split up these four soil-conditioning treatments 285 into three contrasts to test: 1) Does it matter whether the soil was conditioned by 
286 plants or not (Soil Non-conditioned/Conditioned $)$ ? 2) When the soil was conditioned by plants, 287 does it matter whether the soil was conditioned by the same species as the focal test 288 plant or by a different species (Soil Home/Away $_{\text {) }}$ 3) When the soil was conditioned by a 289 species different from the focal test plant, does it matter whether the soil was 290 conditioned by an alien or a native species (Soil Alien/Native $_{\text {en }}$ ?

291 Likewise, for the first model (Model.plant.1), which used data from all 292 competition treatments, we created two dummy variables to split up the three 293 competition treatments - no, intra- and interspecific competition - into two contrasts 294 to test: 1) Does it matter whether the test plant was grown with competition 295 (Comp Yes/No $_{2}$ ? 2) When the test plant was grown with competition, does it matter 296 whether the competitor belonged to the same species or not $\left(\mathrm{Comp}_{\text {Intra/Inter }}\right)$ ?

In a few cases of the interspecific competition treatment (103 out of 1573 pots), 298 competitor species were the same as the soil-conditioning species. Therefore, these 299 pots are testing a two-species rather than a three-species interaction. However, 300 removing these data points does not affect the results, indicating that our results are 301 robust (Table S2). It could be that soil-legacy effects are not due to differences in 302 microbial communities of the soil but due to differences in nutrient availability ${ }^{60}$. For 303 example, larger soil-conditioning plants may have left fewer nutrients in the soil, 304 resulting in decreased growth of subsequent test species. To account for this, we 305 added aboveground biomass of the soil-conditioning plant as the covariate in 306 Model.plant.1. We found that aboveground biomass of test plants decreased with that 307 of the soil-conditioning plant (Fig. S1), indicating that nutrient availability might 308 affect test plants. However, adding the covariate did not affect the significance of the 309 other effects (Table S3), indicating that our results are robust. 


\section{0 \\ Analyses of the soil microbial community}

311 To test the effect of soil-conditioning species on soil microbial communities ( $\alpha$ in Fig.

312 1), we used three methods. First, we tested whether the presence of a soil-conditioning

313 plant affected the composition of soil microbial communities, and whether this effect

314 depended on the origin of the soil-conditioning species. To do so, we used

315 permutational analysis of variance (PERMANOVA), as implemented in the adonis

316 function of the vegan package ${ }^{61}$ (Model.soil.1). The models included reads relative

317 abundances of bacteria or fungi as the response variables and soil-conditioning

318 treatment as the explanatory variable. We split up the three soil-conditioning

319 treatments into two contrasts to test: 1) Does it matter whether the soil was

320 conditioned by plants or not? 2) When the soil was conditioned by plants, does it

321 matter whether the species is alien or native?

322 Second, we tested whether alien and native species accumulated putative fungal

323 pathogens, which were identified from FUNGuild, to different degrees. To do so, we

324 used linear mixed models (Model.soil.2) that included the species richness, Shannon

325 diversity or relative abundance of fungal pathogens as the response variable, and soil-

326 conditioning treatments, which were again split up into two contrasts, as the fixed

327 effect. Because some bacteria might be pathogenic, and $70 \%$ of the fungi could not

328 assigned to functional groups based on FUNGuild, we also applied this analysis to

329 species richness and Shannon diversity of all bacteria and fungi.

330 Third, we analyzed how conditioned soil communities differed 1) among plants

331 from the same alien plant species, 2) among plants from the same native species, 3)

332 among different alien species, 4) among different native species, and 5) between alien

333 and native species. To do so, we used linear mixed models (Model.soil.3) and

334 included averaged Bray-Curtis dissimilarities as the response variable, and the five 
335 above-mentioned categories of plant combinations as the fixed effect. The Bray-

336 Curtis dissimilarities of bacteria, fungi, fungal pathogens or fungal endophytes were

337 first calculated between all possible pairs of samples, and then averaged across

338 replicates to get average values for each within-species pair or between-species pair.

339 We split up the five categories of plant combinations into four contrasts to test: 1) Are

340 soil communities more similar (or different) when conditioned by the same plant

341 species than by another species? 2) When conditioned by the same species, are soil

342 communities more similar for alien species than for native species? When conditioned

343 by different species, 3 ) are soil communities more similar between two alien species

344 than between an alien and a native species, and 4) are soil communities more similar

345 for the latter than between two native species? We used heatmaps to visualize the

346 community dissimilarities, whose values were mean-centered and then bounded to

347 range from -1 to 1 . This was done with the corrplot package ${ }^{62}$.

348 After testing the effect of soil-conditioning species on soil bacterial and fungal

349 communities ( $\alpha$ in Fig. 1), we aimed to identify which aspect of soil microbes

350 explained the legacy effect of soil-conditioning species on test plants (i.e. which

351 component of $\alpha$ explained the $\beta$ s in Fig. 1). Because the analyses of plant performance

352 revealed that the third species rarely significantly affected the strength of competition

353 (i.e. on average, $\beta_{\text {inter }}$ and $\beta_{\text {intra }}$ did not differ significantly from 0 ), we present the

354 analyses of effects of $\alpha$ on $\beta_{\text {inter }}$ (or $\beta_{\text {intra }}$ ) in the supplement S6.

355 We first tested whether diversity and abundance of potential soil enemies (one 356 aspect of $\alpha$ ) explained the soil-legacy effect on growth of test plants $\left(\beta_{\text {alone }}\right)$. To do so, 357 we used linear mixed models (Model.link.1) and included the soil-legacy effect $358\left(\beta_{\text {alone }}\right)$ as the response variable, and diversities of all soil bacteria, all fungi or the 359 subset of fungal pathogens (or the relative abundance of fungal pathogens) as the 
360 fixed effects. Because the enemy release hypothesis predicts that alien species should

361 have less chance to encounter enemies than native species $^{35,63}$, we also added origin of

362 test species and their interaction with diversities of soil bacteria, fungi or fungal

363 pathogens (or relative abundance of fungal pathogens) as fixed effects. The soil-

364 legacy effect, $\beta_{\text {alone }, i, j}$, was calculated as

$$
\beta_{\text {alone }, i, j}=\ln \text { biomass }_{i, j}-\ln \text { biomass }_{i, 0}
$$

365 Here, $\ln$ biomass $_{i, j}$ and $\ln$ biomass $_{i, 0}$ are mean aboveground biomass of test species

$366 i$ when grown without competition (alone) on soil conditioned by species $j$ and on soil 367 not conditioned by plants, respectively. Positive values indicate that soil-conditioning 368 species $j$ improved growth of test species $i$.

369 Second, we tested whether microbial community dissimilarity (another aspect of $370 \alpha$ ) between the soil-conditioning and test species explained the soil-legacy effect 371 ( $\left.\beta_{\text {alone }}\right)$. To do so, we used linear mixed models (Model.link.2) and included the soil372 legacy effect, $\beta_{a l o n e, i, j}$, as the response variable, and included Bray-Curtis 373 dissimilarities between soil-conditioning and test species as the fixed effect. Because 374 three out of ten test species were not included in the soil-conditioning phase, we could 375 not calculate the microbial community dissimilarity between them and the soil376 conditioning species. Consequently, this analysis was restricted to a subset (i.e. 70 out 377 of 100 soil-conditioning species $\times$ test species pairs). 


\section{Results}

379 Do soil-conditioning species affect differences in biomass production (i.e. 380 competitive outcomes)?

381 On average, plants produced less aboveground biomass $\left(-67.2 \% ; \chi^{2}=10.31, P=\right.$ 382 0.001) on conditioned soil than on non-conditioned soil, and on home soil (i.e. soil 383 conditioned by the same plant species) than on away soil $\left(-22.7 \% ; \chi^{2}=4.54, P=\right.$

384 0.033; Fig. 3a; Table 1). Biomass of alien and native plants did not significantly differ 385 across soil-conditioning treatments and competition treatments $\left(\chi^{2}=0.083, P=0.774\right.$;

386 Fig. 3a; Table 1). Compared to non-conditioned soil, conditioned soil did not change 387 the difference in biomass between alien and native plants across competition 388 treatments $\left(\right.$ Origin $\times$ Soil $_{\text {Non-conditioned/Conditioned }}$ interaction: $\left.\chi^{2}=1.395, P=0.238\right)$.

389 However, when grown on alien soil (i.e. soil conditioned by an alien plant), alien 390 plants produced significantly more aboveground biomass $(+18.2 \%)$ than native plants, 391 whereas on native soil, this difference was smaller $\left(+9.9 \%\right.$; Origin $\times$ Soil $_{\text {Alien/Native }}$ 392 interaction: $\chi^{2}=4.74, P=0.029$; Fig 3a; Table 1). This indicates that soil conditioning 393 with an alien plant pushed the competitive outcome more strongly towards subsequent 394 aliens than soil conditioning with a native plant.

\section{Do soil-conditioning species affect growth and the strength of competition?}

396 For the subset of plants grown alone (competition-free), aboveground biomass was

397 lower on conditioned soil than on non-conditioned soil $\left(-59.8 \% ; \chi^{2}=13.38, P<\right.$ 398 0.001; Fig. 3b; Table S4). The competition-free plants also tended to produce less 399 biomass on home soil than on away soil (Fig. 3b). This effect was not significant for 400 aboveground biomass, but was marginally significant for belowground biomass ($40115.0 \% ; \chi^{2}=2.93, P=0.087$; Fig. $3 b \&$ S2; Table S4). Averaged across all soil402 conditioning treatments, alien and native competition-free plants did not differ in 403 biomass production $\left(\chi^{2}=0.025, P=0.875\right)$. However, aliens achieved more 
404 aboveground biomass (+17.3\%) than natives on alien soil, whereas on native soil, this

405 difference was smaller (+8.5\%; Fig. 3b; Table S4). Although this difference was only

406 marginally significant for aboveground biomass $\left(\chi^{2}=2.90, P=0.088\right)$ and

407 belowground biomass $\left(\chi^{2}=3.23, P=0.072\right)$, it was significant for total biomass $\left(\chi^{2}=\right.$

408 4.56, $P=0.033$; Table S4; Fig. S2). This result indicates that soil conditioning with an

409 alien plant reduced growth of subsequent alien plants to a lesser degree than growth of

410 subsequent native plants.

411 Competition reduced aboveground biomass $\left(-35.1 \% ; \chi^{2}=3.74, P=0.053\right.$; Fig.

$4123 \mathrm{c}$; Table 1), and was more intense when the test plants were grown on alien soil than

413 on native soil $\left(-39.3 \%\right.$ vs. $-33.0 \% ; \chi^{2}=4.85, P=0.028$; Fig $3 \mathrm{c}$; Table 1$)$. However,

414 the strength of competition was not affected by the other soil-conditioning treatments.

415 Alien and native test species did not differ in their biomass responses to competition

$416\left(\chi^{2}=0.25, P=0.618\right)$, and this finding holds for each of the soil-conditioning

417 treatments. We also found that intra- and interspecific competition did not differ in

418 strength $\left(\chi^{2}=0.80, P=0.373\right)$, and that this finding holds for alien and native test

419 species, and for each of the soil-conditioning treatments (Fig 3c; Table 1).

420 Do soil microbial communities explain the soil-legacy effect?

421 Overall, the presence of plants significantly modified the composition of soil bacterial

422 and fungal communities (Supplement S4.1). Moreover, alien and native plant species

423 modified the composition of bacterial and fungal communities differently

424 (Supplement S4.1). However, neither the presence of plants nor the origin of plants

425 significantly affected relative abundance of fungal pathogens and diversities of

426 bacteria, all fungi and the subset of fungal pathogens (Supplement S4.2). Further

427 analyses showed that, the legacy effect of soil-conditioning species on test species

428 that were grown alone $\left(\beta_{\text {alone }}\right)$ was not correlated to relative abundance of fungal 
429 pathogens and diversities of bacteria, fungi and fungal pathogens, and that this holds 430 for both native and alien test species (Supplement S5.1).

431 The compositions of soil bacterial communities were less similar (i.e. more blue 432 colors in Fig. 4) between individual plants of different species than between plants of 433 the same species $\left(\chi^{2}=4.31, P=0.038\right.$; Fig. 4a \& e; Table S9). Although this was not 434 the case for fungal communities, their dissimilarity depended on the origins of the 435 species in the between-species combination (Fig. 4b-d \& f-h; Table S9). Specifically, 436 compositions of fungal communities as a whole and of the subset of fungal 437 endophytes were less similar between two alien plant species than between an alien 438 and a native species (Fungi: $\chi^{2}=4.00, P=0.045$; Fungal endophytes: $\chi^{2}=12.11, P=$ 439 0.001). In addition, the compositions of fungal endophyte communities were less 440 similar between an alien and a native species than between two natives $\left(\chi^{2}=10.53, P\right.$ $441=0.001 ;$ Fig. $4 \mathrm{~d} \&$ h; Table S9).

442 For the subset data on dissimilarities of soil communities between soil443 conditioning and test species, we found that the legacy effect of soil-conditioning 444 species on test species grown alone $\left(\beta_{\text {alone }}\right)$ became less negative with decreasing 445 similarity of their fungal endophyte communities $\left(\chi^{2}=7.49, P=0.006\right.$; Fig. 5d; Table 446 S13). A similar marginally significant trend was found for bacteria $\left(\chi^{2}=2.78, P=\right.$ 447 0.096; Fig. 5a; Table S13). For the other groups of microbiota, i.e. fungi overall and 448 fungal pathogens, the soil-legacy effect $\left(\beta_{\text {alone }}\right)$ was not significantly correlated to the 449 dissimilarity of soil communities (Fig. 5b \& c; Table S13). 


\section{Discussion}

451 We found that when grown on soil that had not been conditioned by plants, alien and

452 native plants produced similar biomasses across competition treatments. The same

453 was true on soil that had been conditioned by plants. This indicates that overall, the

454 naturalized aliens in our study were not more competitive than natives, and that the

455 presence of soil-conditioning species did not change this competitive outcome.

456 However, on soil that had been conditioned by aliens, aliens produced more biomass

457 than natives and thus were more competitive. Analysis of biomass of plants grown

458 alone (without competition) indicated that conditioning by aliens changed the

459 competitive outcomes by affecting growth of aliens less negatively than that of

460 natives. The strength of competition, however, was rarely affected by the soil-

461 conditioning treatment. Our analysis of soil microbiomes revealed that the legacy

462 effect of soil-conditioning species on test species became less negative as their fungal

463 endophyte communities became less similar, and that fungal endophyte communities

464 were less similar between two aliens than between aliens and natives. This suggests

465 that the less negative effect of conditioning by aliens on other aliens is partly driven

466 by a lower chance of spill-over of pathogenic fungal endophytes between aliens.

\section{Invasional meltdown in a multispecies context}

468 The similar aboveground biomass of aliens and natives on soil that had not been

469 conditioned or had been conditioned by native plants indicates that on those soils

470 aliens are not more competitive than natives. This result is in line with the recent

471 finding that alien and native species do not differ in their competitive abilities if both

472 of them are widespread and abundant species ${ }^{5}$, as was the case in our study. However,

473 on soil conditioned by aliens, aliens were more competitive than natives. This finding

474 supports the idea of invasional meltdown $n^{3,13,14}$ and partly explains the frequent co- 
475 occurrence of alien species $^{10}$. So far, over 13,000 plant species have become

476 naturalized outside their natural ranges ${ }^{64,65}$, and in some regions more than half of the

477 flora consists of naturalized alien species ${ }^{66}$. These numbers are still increasing ${ }^{67}$,

478 which means that interactions between alien species are likely to become more and

479 more frequent. Our findings indicate that the relative facilitation between aliens,

480 mediated by soil microbes, may accelerate the naturalization of aliens and their

481 competitive impacts on natives.

483 intraspecific competition is generally stronger than interspecific competition ${ }^{68}$. We

484 nevertheless did not find a difference between the strengths of intra- and interspecific

485 competition. Probably, resource competition was not intense in our study as we

486 fertilized the plants regularly. It is worth noting, however, that in our study, plants

487 grew worse on home soil than on away soil. In other words, intraspecific apparent

488 competition (soil-microbes-mediated intraspecific competition) was stronger than

489 interspecific apparent competition. Consequently, alien plants were still self-limited.

490 However, alien plants would gain an advantage if they were less limited by

491 intraspecific apparent competition than natives were, which was supported by many

492 studies $^{30}$ but not ours. One possible reason for this discrepancy is the low statistical

493 power in our study. Only two of the five alien test species were grown on home soil as

494 we partly had different species in the soil-conditioning and test phases. Another

495 reason could be that we used successful native species (i.e. widespread and locally

496 abundant). Their intraspecific apparent competition might be weaker than for less

497 successful native species ${ }^{69}$, and thus similar with that of the successful aliens.

498 It is debated in ecology whether it is possible to predict competitive outcomes in 499 multispecies communities solely based on pairwise interactions. The results of our 
500 experiment suggest that this indeed is possible. For example, from the data of plants 501 that were grown alone, which tested pairwise interactions between soil-conditioning 502 and test species, we showed that alien test species produced more biomass than 503 natives on soil that had been conditioned by aliens. This finding still holds when we 504 also included the data of plants that were grown with competition to assess 505 competitive outcomes in multispecies communities. Moreover, the soil-conditioning 506 species rarely changed the strength of competition. When they did, they affected the 507 strength of competition equally for alien and native species, and thus did not affect 508 competitive outcomes. This finding echoes those of some other experiments. For 509 example, a phytoplankton experiment by Prince, et al. ${ }^{23}$ found that the strength of 510 competition was modified only in two out of the ten species in their study. Friedman, 511 et al. ${ }^{20}$ found that competitive outcomes in three-species bacterial communities were 512 predicted by pairwise outcomes with an accuracy of $90 \%$. Therefore, we might in 513 most cases be able to scale up from pairwise interactions to at least three-species 514 interactions.

515 However, it might be too soon to scale up to systems with more than three 516 species. Friedman, et al. ${ }^{20}$ found that pairwise outcomes alone poorly predict 517 outcomes of seven- or eight-species bacterial communities. This could indicate that 518 with increasing diversity the likelihood increases that the strength of pairwise 519 competition is modified by at least one of the many other species in the community. 520 Future experiments that test competition between alien and native organisms in more 521 diverse communities could shed light on this hypothesis. However, as competition 522 occurs locally ${ }^{70}$, it is unlikely that more than a handful of species compete at the same 523 time. Consequently, we believe that our experiment and results are representative for 524 plant invasions in the real world. 


\section{Potential mechanisms underlying invasional meltdown}

526 We did not find evidence for release of soil enemies ${ }^{71}$. At the end of the soil527 conditioning phase, alien and native plant species did not differ in the diversity and 528 relative abundance of fungal pathogens. In addition, diversity and relative abundance 529 of fungal pathogens in the soil did not significantly explain the performance of alien 530 and native species in the test phase. This lack of evidence for enemy release contrasts 531 with the findings that enemy release contributed to plant invasion ${ }^{72,73}$, but see ref ${ }^{63}$. 532 This discrepancy may first arise from the incomplete information on the functional 533 roles of bacteria and fungi. The functional roles of bacteria are hard to identify, and 534 over $70 \%$ of the ITS reads in our study could not assigned to functional groups using 535 FUNGuild. In addition, previous studies mainly focused on aboveground enemies and 536 on herbivores. Belowground microbial enemies are more diverse and far less known, 537 and many of them might be rare or less harmful. Therefore, diversity and relative 538 abundance of soil pathogens may be less likely to capture the mechanism underlying 539 soil-legacy effect than the actual identities of the pathogens. Indeed, we found that 540 alien and native plants modified the composition of soil microbial communities in 541 different ways (Supplement S4.1). This suggests that the soil-legacy effect is mainly

542 mediated by the community structure of the soil microbial communities and less by 543 the diversity and abundance.

544 Interestingly, we found that the compositions of fungal endophyte communities 545 were less similar between alien plant species than between aliens and natives, and less 546 similar than between natives. We found, however, a similar pattern when the field-soil 547 inoculate used in the soil-conditioning phase had been sterilized (Fig. S8; Table S10). 548 This suggests that the high dissimilarity of fungal endophyte communities between 549 aliens is likely driven by endophytes that were already present in the plants before 
550 transplanting (e.g. as seed microbiota) rather than by those that were in the field-soil 551 inoculum.

552 There are three potential reasons why compositions of fungal endophyte 553 communities were less similar between two aliens than between other origin 554 combinations. First, as we found that fungal endophyte communities became less 555 similar with increasing phylogenetic distance between plant species (Supplement S7), 556 it could be that the phylogenetic distance between aliens was higher than between 557 aliens and natives, and also higher than between natives. However, as this was not the 558 case (Supplement S7), this explanation can be discarded. A second potential 559 explanation could be that natives have co-occurred with each other for a longer time, 560 and thus share more similar endophytes ${ }^{74}$. A third potential explanation could be that 561 if the alien species brought endophytes with them from their native ranges ${ }^{75}$, these 562 endophytes jumped over to native hosts. Such host shifts of endophytes are more 563 likely to involve native plants than other alien plants, as alien-native interactions are 564 still more common than alien-alien interactions. Regardless of the exact reason, the 565 observed differences in fungal endophyte communities suggest that they might play a 566 role in the difference in soil-legacy effects.

In line with this idea, we found that the legacy effect of soil-conditioning species 568 on test species became less negative with decreasing similarity in their fungal 569 endophyte communities. As about $40 \%$ of the assigned endophytes were pathogenic, 570 the overall effect of endophytes might be negative. Consequently, when one plant 571 species cultivated very different endophyte communities compared to another, 572 endophytes remaining in the soil matrix (e.g. root endophytes) were unlikely to infect 573 and negatively affect the other. This finding, together with the higher difference in 574 fungal endophyte communities between alien plant species than between alien and 
575 native plants species, provides a novel explanation for invasional meltdown. Still, the

576 roles of endophytes are not well understood. Their effects depend on the environment

577 and can range from pathogenic to mutualistic ${ }^{76,77}$. As a result, the legacy effect

578 mediated by endophytes might even change with soil type. More experimental

579 evidence for their role in soil-legacy effects and plant invasions is required.

580 Manipulative studies based on synthetic microbial communities ${ }^{78}$ might shed light on

581 the roles of endophytes in plant competition and invasion success.

\section{Conclusions}

583 Our results indicate that the accumulation of alien species may be accelerated in the

584 future, because aliens could favor other aliens over natives through soil-legacy effects, 585 mediated by soil microbial communities (i.e. apparent competition). Since Charles 586 Darwin $^{39}$, novelty has been posited as an important mechanism of invasion, as it 587 allows aliens to occupy niches that are not used by natives ${ }^{79-81}$. Here, we unveiled 588 another role of novelty, which could decrease spill-over of endophytes between alien 589 plant species, some of which are pathogenic. Consequently, alien species in our study 590 suppressed each other less than they suppressed natives, and this could lead to 591 invasional meltdown. 


\section{Acknowledgements}

593 We thank L. Arnold, S. Berg, O. Ficht, M. Fuchs, S. Gommel, E. Mamonova, V.

594 Pasqualetto, C. Rabung, B. Rüter, B. Speißer, H. Vahlenkamp and E. Werner for

595 practical assistance. ZZ was funded by the China Scholarship Council

596 (201606100049) and supported by the International Max Planck Research School for

597 Organismal Biology. YL was funded by the Chinese Academy of Sciences

598 (Y9H1011001, Y9B7041001).

599

600 Author contributions

$601 \mathrm{ZZ}$ conceived the idea. ZZ, YL and MvK designed the experiment. ZZ, YL and CB

602 performed the experiment. ZZ analyzed the data and wrote the manuscript with input 603 from all others.

604 


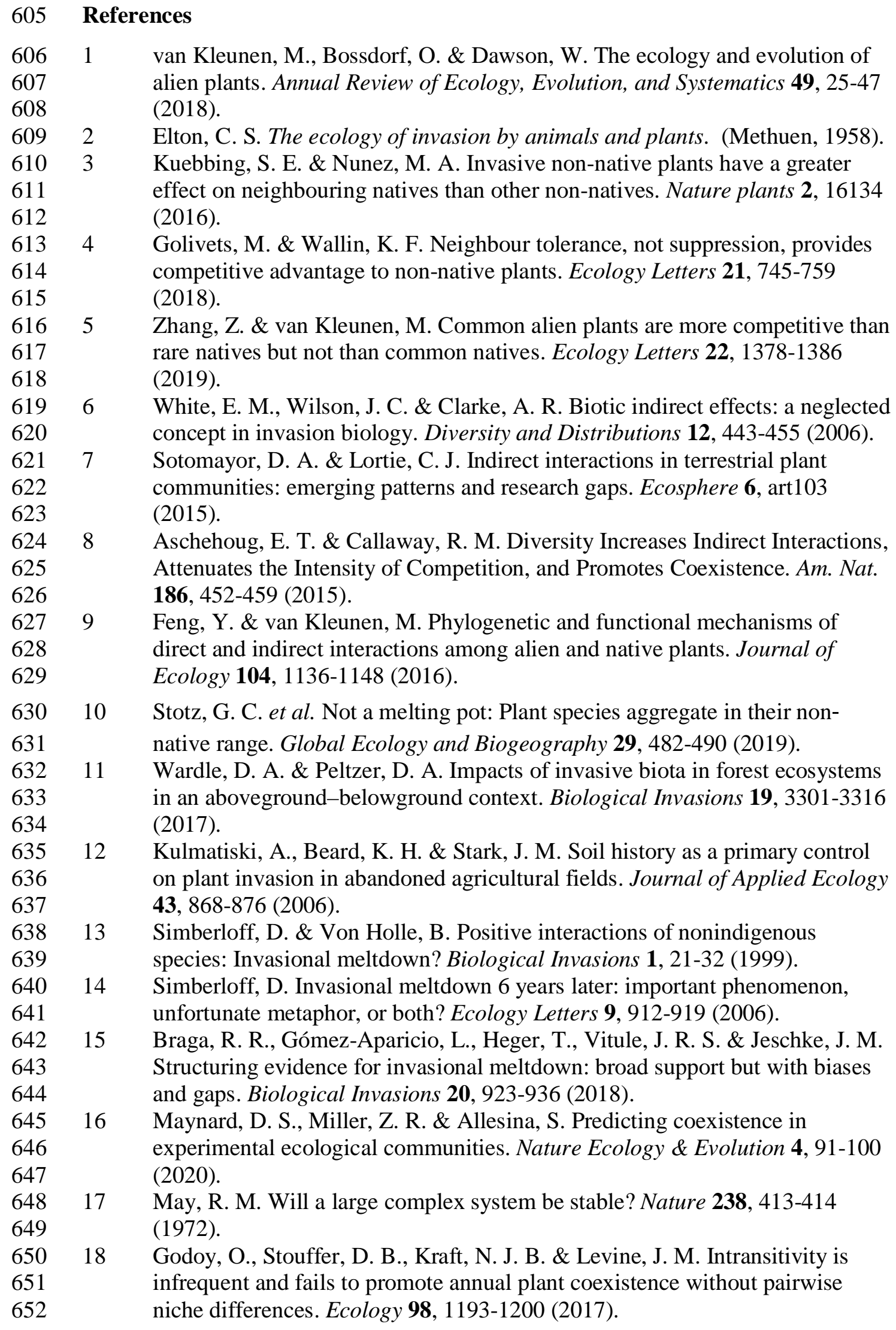


65319 Vandermeer, J. H. The competitive structure of communities: An experimental

654

655

656

657

658

659

660

661

662

663

664

665

666

667

668

669

670

671

672

673

674

675

676

677

678

679

680

681

682

683

684

685

686

687

688

689

690

691

692

693

694

695

696

697

698

699

700 approach with protozoa. Ecology 50, 362-371 (1969).

20 Friedman, J., Higgins, L. M. \& Gore, J. Community structure follows simple assembly rules in microbial microcosms. Nature Ecology \& Evolution 1, 0109 (2017).

21 Case, T. J. \& Bender, E. A. Testing for higher order interactions. The American Naturalist 118, 920-929 (1981).

22 Levine, J. M., Bascompte, J., Adler, P. B. \& Allesina, S. Beyond pairwise mechanisms of species coexistence in complex communities. Nature 546, 5664 (2017).

23 Prince, E. K., Myers, T. L., Naar, J. \& Kubanek, J. Competing phytoplankton undermines allelopathy of a bloom-forming dinoflagellate. Proceedings of the Royal Society B: Biological Sciences 275, 2733-2741 (2008).

24 Tilman, D. Resource competition and community structure. (Princeton University Press, 1982).

25 Dawson, W., Fischer, M. \& van Kleunen, M. Common and rare plant species respond differently to fertilisation and competition, whether they are alien or native. Ecology Letters 15, 873-880 (2012).

26 Godoy, O., Valladares, F. \& Castro-Díez, P. Multispecies comparison reveals that invasive and native plants differ in their traits but not in their plasticity. Functional Ecology 25, 1248-1259 (2011).

27 Liu, Y. J. \& van Kleunen, M. Nitrogen acquisition of Central European herbaceous plants that differ in their global naturalization success. Functional Ecology 33, 566-575 (2019).

28 Holt, R. D. Predation, apparent competition, and the structure of prey communities. Theoretical population biology 12, 197-229 (1977).

29 Bever, J. D., Westover, K. M. \& Antonovics, J. Incorporating the soil community into plant population dynamics: The utility of the feedback approach. Journal of Ecology 85, 561-573 (1997).

30 Kulmatiski, A., Beard, K. H., Stevens, J. R. \& Cobbold, S. M. Plant-soil feedbacks: a meta-analytical review. Ecology Letters 11, 980-992 (2008).

31 Lekberg, Y. et al. Relative importance of competition and plant-soil feedback, their synergy, context dependency and implications for coexistence. Ecology Letters 21, 1268-1281 (2018).

32 Latz, E. et al. Plant diversity improves protection against soil-borne pathogens by fostering antagonistic bacterial communities. Journal of Ecology 100, 597604 (2012).

33 Kardol, P., Cornips, N. J., van Kempen, M. M. L., Bakx-Schotman, J. M. T. \& van der Putten, W. H. Microbe-mediated plant-soil feedback causes historical contingency effects in plant community assembly. Ecological Monographs 77, 147-162 (2007).

34 Dawson, W., Schrama, M. \& Austin, A. Identifying the role of soil microbes in plant invasions. Journal of Ecology 104, 1211-1218 (2016).

35 Callaway, R. M., Thelen, G. C., Rodriguez, A. \& Holben, W. E. Soil biota and exotic plant invasion. Nature 427, 731 (2004).

36 Ke, P. J. \& Wan, J. Effects of soil microbes on plant competition: a perspective from modern coexistence theory. Ecological Monographs $\mathbf{9 0}$, e01391 (2020). 
70137 Kuebbing, S. E., Classen, A. T., Call, J. J., Henning, J. A. \& Simberloff, D.

702

703

704

705

706

707

708

709

710

711

712

713

714

715

716

717

718

719

720

721

722

723

724

725

726

727

728

729

730

731

732

733

734

735

736

737

738

739

740

741

742

743

744

745

746

747

748

749

750

Plant-soil interactions promote co-occurrence of three nonnative woody shrubs. Ecology 96, 2289-2299 (2015).

38 Callaway, R. M. et al. Novel weapons: Invasive plant suppresses fungal mutualists in america but not in its native europe. Ecology 89, 1043-1055 (2008).

39 Darwin, C. On the origin of species. (J. Murrary, 1859).

40 Keane, R. M. \& Crawley, M. J. Exotic plant invasions and the enemy release hypothesis. Trends in Ecology \& Evolution 17, 164-170 (2002).

41 Mangla, S. \& Callaway, R. M. Exotic invasive plant accumulates native soil pathogens which inhibit native plants. Journal of Ecology 96, 58-67 (2008).

42 Saul, W. C. \& Jeschke, J. M. Eco-evolutionary experience in novel species interactions. Ecology Letters 18, 236-245 (2015).

43 van Kleunen, M., Dawson, W., Bossdorf, O. \& Fischer, M. The more the merrier: Multi-species experiments in ecology. Basic and Applied Ecology 15, 1-9 (2014).

44 Bundesamt für Naturschutz. (http://www.floraweb.de/, 2003).

45 Richardson, D. M. et al. Naturalization and invasion of alien plants: concepts and definitions. Diversity and Distributions 6, 93-107 (2000).

46 Brinkman, E. P., Van der Putten, W. H., Bakker, E.-J. \& Verhoeven, K. J. F. Plant-soil feedback: experimental approaches, statistical analyses and ecological interpretations. Journal of Ecology 98, 1063-1073 (2010).

47 Klindworth, A. et al. Evaluation of general 16S ribosomal RNA gene PCR primers for classical and next-generation sequencing-based diversity studies. Nucleic Acids Research 41, e1 (2013).

48 Orgiazzi, A. et al. Unravelling soil fungal communities from different Mediterranean land-use backgrounds. PLoS One 7, e34847 (2012).

49 Martin, M. Cutadapt removes adapter sequences from high-throughput sequencing reads. EMBnet.journal 17, 10-13 (2011).

50 Callahan, B. J. et al. DADA2: High-resolution sample inference from Illumina amplicon data. Nat Methods 13, 581-583 (2016).

51 Nilsson, R. H. et al. The UNITE database for molecular identification of fungi: handling dark taxa and parallel taxonomic classifications. Nucleic Acids Research 47, D259-D264 (2018).

52 Nguyen, N. H. et al. FUNGuild: An open annotation tool for parsing fungal community datasets by ecological guild. Fungal Ecology 20, 241-248 (2016).

$53 \quad R$ : A language and environment for statistical computing (R Foundation for Statistical Computing, Vienna, Austria. Available at: http://www.Rproject.org/. 2019).

54 Pinheiro, J., Bates, D., DebRoy, S., Sarkar, D. \& R Core Team. Linear and nonlinear mixed effects models. R package version 3, 57 (2018).

55 Gibson, D., Connolly, J., Hartnett, D. \& Weidenhamer, J. Designs for greenhouse studies of interactions between plants. Journal of Ecology 87, 1-16 (1999).

56 Aschehoug, E. T., Brooker, R., Atwater, D. Z., Maron, J. L. \& Callaway, R. $\mathrm{M}$. The mechanisms and consequences of interspecific competition among plants. Annual Review of Ecology and Systematics 47, 263-281 (2016).

57 Hart, S. P., Burgin, J. R. \& Marshall, D. J. Revisiting competition in a classic model system using formal links between theory and data. Ecology 93, 20152022 (2012). 
75158 Zuur, A., Ieno, E., Walker, N., Saveliev, A. \& Smith, G. Mixed effects models

752

753

754

755

756

757

758

759

760

761

762

763

764

765

766

767

768

769

770

771

772

773

774

775

776

777

778

779

780

781

782

783

784

785

786

787

788

789

790

791

792

793

794

795

796

797

798

799

and extensions in ecology with R. Gail M, Krickeberg K, Samet JM, Tsiatis A, Wong W, editors. New York, NY: Spring Science and Business Media (2009).

59 Schielzeth, H. Simple means to improve the interpretability of regression coefficients. Methods Ecol. Evol. 1, 103-113 (2010).

60 Bennett, J. A. \& Klironomos, J. Mechanisms of plant-soil feedback: interactions among biotic and abiotic drivers. New Phytologist 222, 91-96 (2019).

61 Oksanen, J. et al. The vegan package. (2019).

62 Wei, T. \& Simko, V. corrplot: Visualization of a correlation matrix (Version 0.84). (2017).

63 Chun, Y. J., van Kleunen, M. \& Dawson, W. The role of enemy release, tolerance and resistance in plant invasions: linking damage to performance. Ecology Letters 13, 937-946 (2010).

64 van Kleunen, M. et al. Global exchange and accumulation of non-native plants. Nature 525, 100-103 (2015).

65 Pyšek, P. et al. Naturalized alien flora of the world. Preslia 89, 203-274 (2017).

66 Essl, F. et al. Drivers of the relative richness of naturalized and invasive plant species on Earth. AoB PLANTS 11, plz051 (2019).

67 Seebens, H. et al. Global rise in emerging alien species results from increased accessibility of new source pools. Proceedings of the National Academy of Sciences 115, E2264 (2018).

68 Adler, P. B. et al. Competition and coexistence in plant communities: intraspecific competition is stronger than interspecific competition. Ecol Lett (2018).

69 Mangan, S. A. et al. Negative plant-soil feedback predicts tree-species relative abundance in a tropical forest. Nature 466, $752-755$ (2010).

70 Dal Co, A., van Vliet, S., Kiviet, D. J., Schlegel, S. \& Ackermann, M. Shortrange interactions govern the dynamics and functions of microbial communities. Nature Ecology \& Evolution (2020).

71 Reinhart, K. O., Packer, A., Van der Putten, W. H. \& Clay, K. Plant-soil biota interactions and spatial distribution of black cherry in its native and invasive ranges. Ecology Letters 6, 1046-1050 (2003).

72 Liu, H. \& Stiling, P. Testing the enemy release hypothesis: a review and metaanalysis. Biological Invasions 8, 1535-1545 (2006).

73 Zhang, Z. et al. Contrasting effects of specialist and generalist herbivores on resistance evolution in invasive plants. Ecology 99, 866-875 (2018).

74 Dickie, I. A. et al. The emerging science of linked plant-fungal invasions. New Phytologist 215, 1314-1332 (2017).

75 Shipunov, A., Newcombe, G., Raghavendra, A. K. H. \& Anderson, C. L. Hidden diversity of endophytic fungi in an invasive plant. American Journal of Botany 95, 1096-1108 (2008).

76 Hardoim, P. R. et al. The hidden world within plants: Ecological and evolutionary considerations for defining functioning of microbial endophytes. Microbiology and Molecular Biology Reviews 79, 293-320 (2015).

77 Busby, P. E., Peay, K. G. \& Newcombe, G. Common foliar fungi of Populus trichocarpa modify Melampsora rust disease severity. New Phytologist 209, 1681-1692 (2016). 
$80078 \quad$ Großkopf, T. \& Soyer, O. S. Synthetic microbial communities. Current

$801 \quad$ Opinion in Microbiology 18, $72-77$ (2014).

80279 Divíšek, J. et al. Similarity of introduced plant species to native ones

803 facilitates naturalization, but differences enhance invasion success. Nature

$804 \quad$ communications $\mathbf{9}, 4631$ (2018).

$80580 \quad$ Feng, Y., Fouqueray, T. D., van Kleunen, M. \& Cornelissen, H. Linking

806 Darwin's naturalisation hypothesis and Elton's diversity-invasibility

807 hypothesis in experimental grassland communities. Journal of Ecology 107,

808 794-805 (2019).

80981 Li, S. P. et al. The effects of phylogenetic relatedness on invasion success and

810 impact: deconstructing Darwin's naturalisation conundrum. Ecology Letters

$811 \quad \mathbf{1 8}, 1285-1292(2015)$.

812

813 


\section{Tables and figures}

815 Table 1 Effects of soil treatments, competition treatments, origin of test species

816 and their interactions on aboveground biomass of plants. Significant effects $(\mathrm{P}<$

$8170.05)$ are in bold and marked with asterisks, and marginally significant effects $(0.05 \leq$

$818 \mathrm{P}<0.1)$ are in italics and marked with a dagger symbol.

\begin{tabular}{|c|c|c|}
\hline & $\chi^{2}$ & $\mathbf{P}$ \\
\hline Transplanting date & 12.815 & $<0.001 *$ \\
\hline Soil $_{\text {Non-conditioned/Conditioned }}$ & 10.306 & $0.001 *$ \\
\hline Soil $_{\text {Home/Away }}$ & 4.535 & $\mathbf{0 . 0 3 3} *$ \\
\hline Soil $_{\text {Alien/Native }}$ & 0.107 & 0.744 \\
\hline Origin $(\mathrm{O})$ & 0.083 & 0.774 \\
\hline Compyes/No & 3.738 & $0.053 \dagger$ \\
\hline Comp $_{\text {Intra/Inter }}$ & 0.795 & 0.373 \\
\hline $\mathrm{O}:$ Soil $_{\text {Non-conditioned/Conditioned }}$ & 1.395 & 0.238 \\
\hline $\mathrm{O}:$ Soil $_{\text {Home/Away }}$ & 1.669 & 0.196 \\
\hline $\mathrm{O}:$ Soil $_{\text {Alien/Native }}$ & 4.741 & $0.029 *$ \\
\hline Soil $_{\text {Non-conditioned/Conditioned }}$ : CompYes/No & 0.956 & 0.328 \\
\hline Soil $_{\text {Non-conditioned/Conditioned }}$ : Comp Intra/IIter & 0.176 & 0.675 \\
\hline Soil $_{\text {Home/Away }}$ : Comp Yes/No & 0.121 & 0.728 \\
\hline Soil $_{\text {Home/Away }}:$ Comp $_{\text {Intra/Inter }}$ & 2.273 & 0.132 \\
\hline Soil $_{\text {Alien/Native }}:$ Comp $_{\text {Yes/No }}$ & 4.846 & $0.028 *$ \\
\hline Soil $_{\text {Alien/Native }}:$ Comp $_{\text {Intra/Inter }}$ & 0.321 & 0.571 \\
\hline O:Comp Yes/No & 0.249 & 0.618 \\
\hline O:Comp Intra/Inter & 0.371 & 0.542 \\
\hline $\mathrm{O}:$ Soil $_{\text {Non-conditioned/Conditioned }}:$ Comp $_{\text {Yes/No }}$ & 0.511 & 0.475 \\
\hline $\mathrm{O}:$ Soil $_{\text {Non-conditioned/Conditioned }}:$ Comp $_{\text {Intra/Inter }}$ & 0.001 & 0.972 \\
\hline $\mathrm{O}:$ Soil $_{\text {Home/Away }}:$ Comp $_{\text {Yes/No }}$ & 1.725 & 0.189 \\
\hline $\mathrm{O}:$ Soil $_{\text {Home/Away }}:$ Comp $_{\text {Intra/Inter }}$ & 0.156 & 0.693 \\
\hline $\mathrm{O}:$ Soil $_{\text {Alien/Native }}:$ Comp $_{\text {Yes/No }}$ & 0.197 & 0.657 \\
\hline $\mathrm{O}:$ Soil $_{\text {Alien/Native }}:$ Comp $_{\text {Intra/Inter }}$ & 0.000 & 0.990 \\
\hline Random effects & SD & \\
\hline Family (focal test) & 0.165 & \\
\hline Species (focal test) & 0.199 & \\
\hline Family (competitor test) & 0.065 & \\
\hline Species (competitor test) & 0.076 & \\
\hline Family (soil) & 0.038 & \\
\hline Species (soil) & 0.031 & \\
\hline Residual & 0.187 & \\
\hline
\end{tabular}



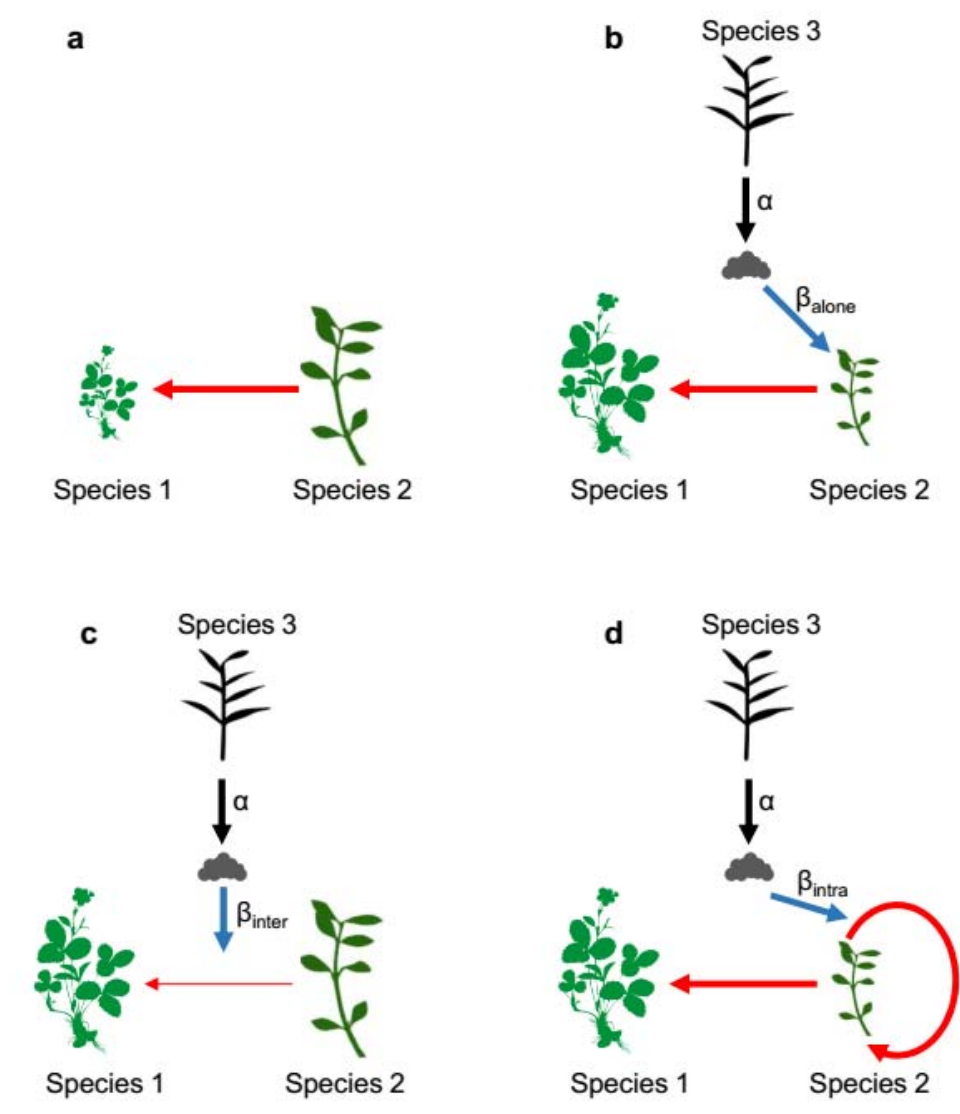

821 Figure 1 Graphical illustration of how a third species can affect competitive outcomes between two species through changes in soil microbial communities. a,

823 In pairwise competition, species 2 suppresses species 1 . Consequently, species 2 is 824 more competitive, as indicated by its larger size. b, By modifying soil microbial 825 communities ( $\alpha$; black arrow), species 3 favors species 1 by suppressing species 2 $826\left(\beta_{\text {alone }}\right)$. Now species 1 is more competitive, as indicated by its larger size. $\mathbf{c}$, Species 3 827 does not suppress species 2, but favors species 1 by lessening the suppression of 828 species 2 on species 1 ( $\beta_{\text {inter; }}$; indicated by the thinner red arrow). d, Species 3 favors 829 species 1 by increasing the suppression of species 2 on itself ( $\beta_{\text {intra }}$; indicated by the 830 presence of a curved red arrow). The overall effect of the third species on competitive 831 outcomes between species 1 and $2, \beta_{\text {total }}$, is the net effect of $\beta_{\text {alone }}, \beta_{\text {inter }}$ and $\beta_{\text {intra. }}$. 


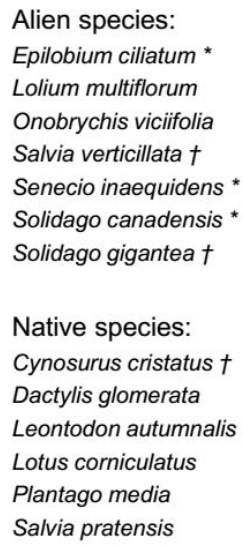

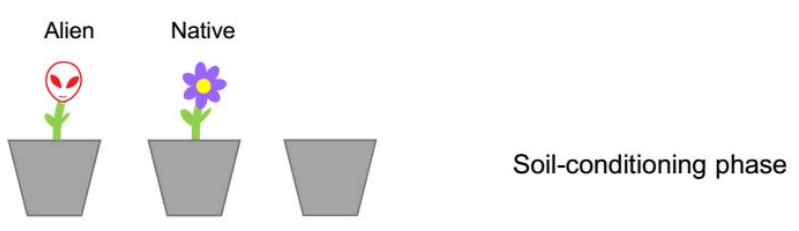

Inoculated with field soil
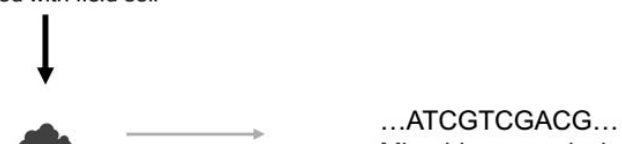

Microbiome analysis
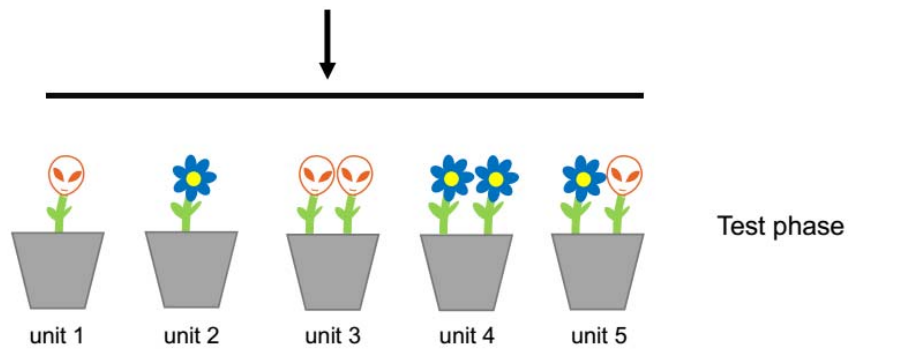

Test phase

833 Figure 2 Graphical illustration of the experimental design. In the soil-conditioning

834 phase, soil was conditioned by one of ten species (either alien or natives), or not

835 conditioned. Then, test species were grown on each of these 11 soils alone or with

836 intra- or interspecific competition. Soil was sampled after conditioning, and amplicon

837 sequencing was used to assess the microbial communities. Plants grown alone (units

838 1-2) were used to test how soil-conditioning species affected the growth of test

839 species ( $\beta_{\text {alone }}$ in Fig. 1). The differences between plants grown in competition (units

840 3-5) and the ones grown alone were used to test how soil-conditioning species

841 affected the strength of intra- and interspecific competition ( $\left.\beta_{\text {intra }} \& \beta_{\text {inter }}\right)$.

842 Aboveground biomass across competition treatments indicated competitive outcomes

843 (i.e. aliens are considered more competitive than natives when they had a higher

844 aboveground biomass across units 1-5), and were used to test how soil-conditioning

845 species affected competitive outcomes $\left(\beta_{\text {total }}\right)$. Species marked with asterisks were 846 only used in the test phase. Species with daggers were only used in the soil847 conditioning phase. Others were used in both phases. 
a

Biomass across competition treatments

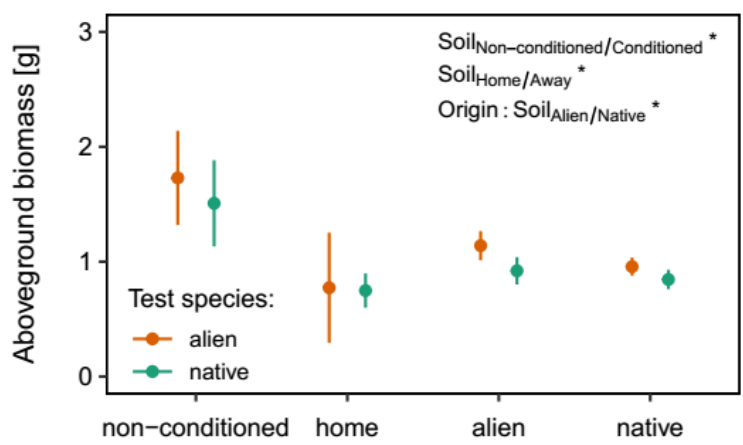

Soil treatment

b

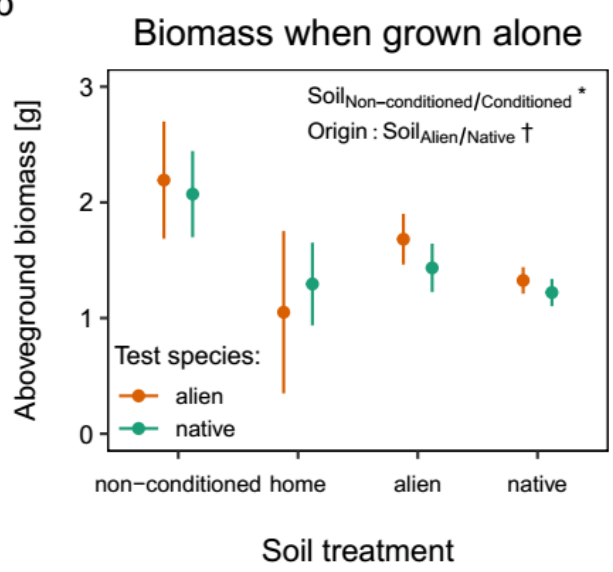

C
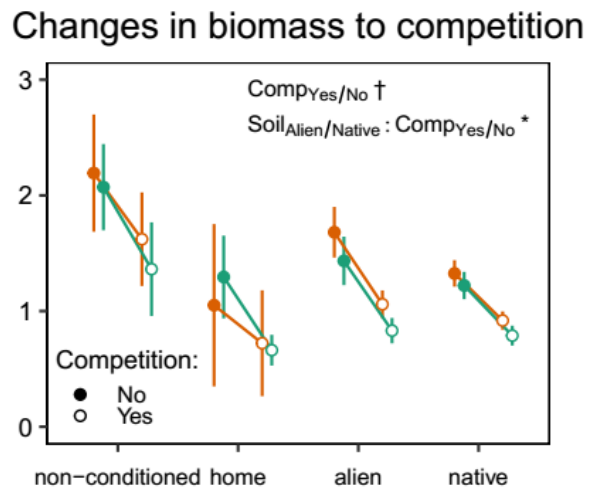

Soil treatment

849 Figure 3 Effects of soil-conditioning treatments on aboveground biomass of alien

850 (orange) and native (green) test species. a, Mean values $( \pm$ SEs) were calculated

851 across competition treatments. Alien test species are considered more competitive

852 than natives when they had a higher aboveground biomass. b, Mean values were

853 calculated based on aboveground biomass of plants grown alone. c, Slopes indicate

854 the strength of competition, that is, the difference in aboveground biomass between

855 plants grown alone (solid dots, the same values as in b) and in competition (open dots).

856 For the soil-conditioning treatments, 'non-conditioned' refers to soil that was not

857 conditioned by any plant, 'home' to soil conditioned by the same species as the test

858 species, and 'alien' and 'native' to soils conditioned by other species than the test 

available under aCC-BY-NC-ND 4.0 International license.

859 species, which were alien or native, respectively. Differences in mean values between

860 different soil treatments in $\mathbf{a}, \mathbf{b}$ and $\mathbf{c}$ indicate differences in $\beta_{\text {total }}, \beta_{\text {alone }}$ and $\beta_{\text {inter }}$ (or

$\left.861 \beta_{\text {intra }}\right)$, respectively. See Fig. 1 for details on $\beta$ s. 

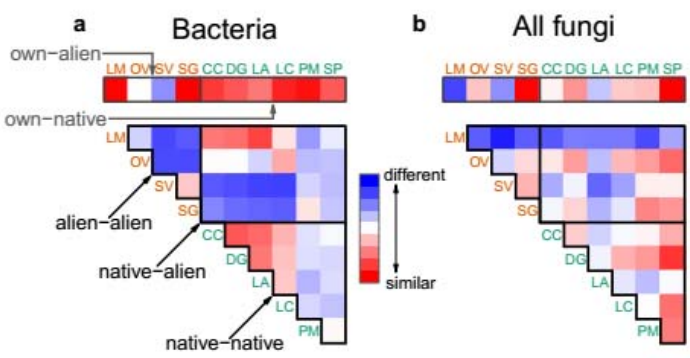

f

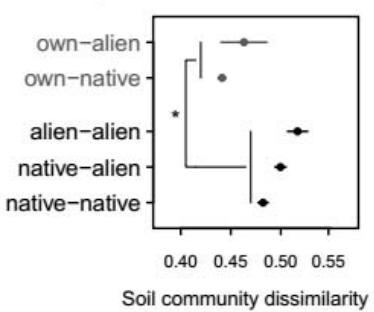

862

863

864

865

866

867

868

869

870

871

873

874

875 individual plants of the same alien plant species; own-native: between plants of the

876 same native species; alien-alien: between plants of different alien species; alien-native:

Figure 4 Dissimilarities of soil microbial communities within and between plant

species. a \& e, bacterial communities; b \& f, fungal communities, c \& $\mathbf{g}$, fungal pathogen communities; $\mathbf{d} \& \mathbf{h}$, fungal endophyte communities. The upper panels show the heatmaps of community dissimilarities of all within-species (top horizontal bars) and between-species combinations (triangular matrices), which are divided into five categories (own-alien, own-native, alien-alien, native-alien, native-native) with black borders. Labels at the top and along the diagonal provide abbreviations of species names (full names in Table S1) of aliens (orange) and natives (green). The colors in the heatmaps represent the relative dissimilarity, with the darkest blue hue representing the highest dissimilarity. The lower panel shows the mean values $( \pm$ SEs) of each of the five categories. Significant differences between categories are indicated with an asterisk (i.e. $\alpha$ in Fig. 1 differs between categories). Own-alien: between

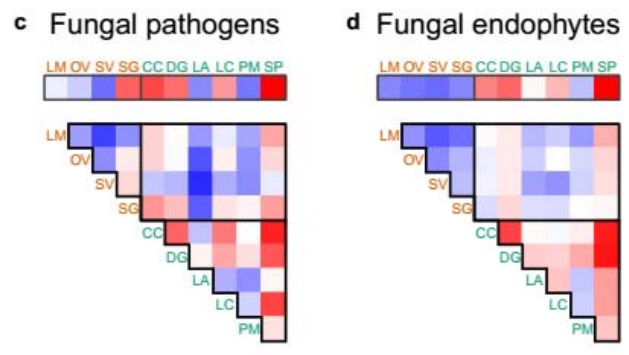

g

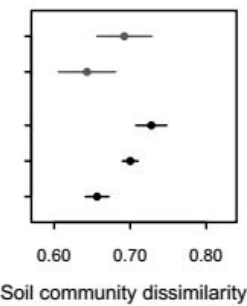

h

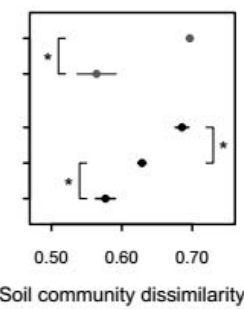


bioRxiv preprint doi: https://doi.org/10.1101/2020.03.11.987867; this version posted June 11, 2020. The copyright holder for this preprint (which was not certified by peer review) is the author/funder, who has granted bioRxiv a license to display the preprint in perpetuity. It is made available under aCC-BY-NC-ND 4.0 International license.

877 between plants of alien and native species; native-native: between plants of different

878 native species. 
a

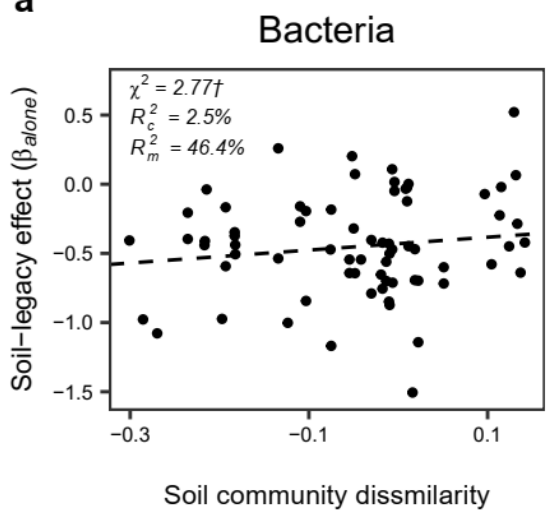

C

Fungal pathogens

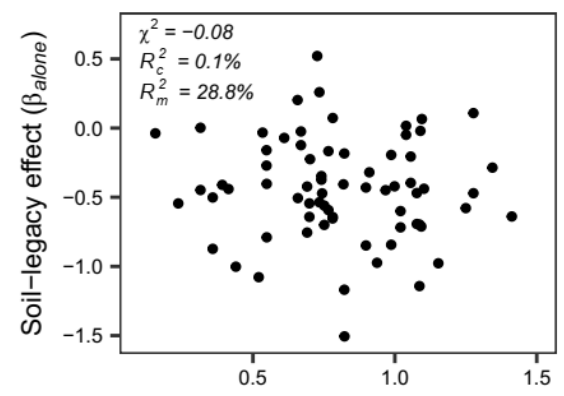

Soil community dissmilarity b

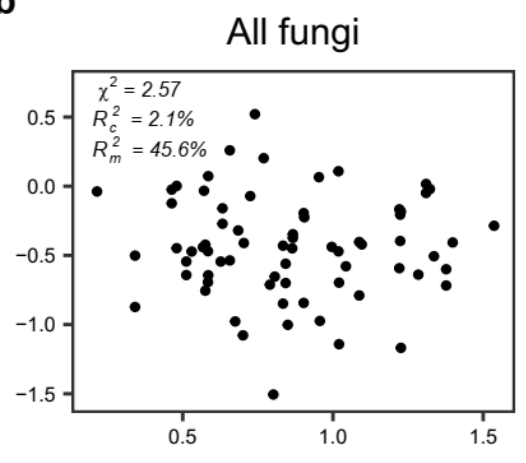

Soil community dissmilarity

d Fungal endophytes

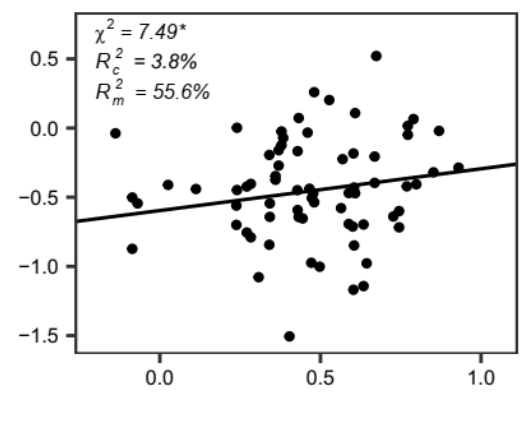

Soil community dissmilarity
879

880

881

884

Figure 5 Effects of soil-community dissimilarity between soil-conditioning and test species on soil-legacy effects. a, bacterial communities; b, fungal communities; $\mathbf{c}$, fungal pathogen communities; $\mathbf{d}$, fungal endophyte communities. Negative values of the soil-legacy effect indicate that plants grew worse on conditioned soil than on nonconditioned soil. Soil-community dissimilarity was logit-transformed. Significant effects of community dissimilarity on soil-legacy effects are indicated with an asterisk (i.e. significant effect of $\alpha$ on $\beta_{\text {alone), and marginally significant effects with a dagger }}$ symbol. Chi-squared value $\left(\chi^{2}\right)$, conditional $\mathrm{R}$ squared $\left(R_{c}^{2}\right)$ and marginal $\mathrm{R}$ squared $\left(R_{m}^{2}\right)$ are reported in each panel. 